\title{
PENERAPAN PENDEKATAN PEMBELAJARAN BRIDGING ANALOGY UNTUK MENINGKATKAN KEMAMPUAN METAKOGNITIF SISWA
}

\author{
ABSTRAK \\ Efriana Jon \\ Sekolah Tinggi Keguruan dan Ilmu Pendidikan (STKIP) \\ Muhammadiyah Sungai Penuh \\ E-mail : efrianajon86@gmail.com
}

Based on the observations and interviews that the authors carried out in SMA Negeri 3 Kerinci obtained information on the average value of the semester odd semester of class $\mathrm{X}$ students is still relatively low, this is because students are not so interested in biology lessons, they quickly feel bored because the applied learning approach still does not provide motivation for students to more spirit in learning. Metacognitive skills also need to be mastered by the teacher so that students can have high metacognitive skills. Because metacognitive skills enable students to plan, keep track of, and monitor their learning. Type of research used is experiment. Population is the entire subject or a large group of research amounted to 47. Sample is partially or representative of the population under study using random sampling technique (randomly). From the final test result in the experimental class using bridging analogy learning approach, the grade averaged 79.57, while in the control class without using bridging analogy learning approach, the average grade was 70.00. After data analysis, obtained tcount $=2.65$ and ttable $=1.68$ turns thitung $>$ ttabel. This means $\mathrm{H} 0$ is rejected and $\mathrm{H} 1$ accepted so it can be concluded that there is influence in the application of bridging analogy learning approach to improve students' metacognitive ability at $95 \%$ confidence level.

Keywords: Learning Approach, Bridging Analogy, Metacognitive Ability.

\section{A. PENDAHULUAN}

Dalam pelaksanaan kebijakan pendidikan di Indonesia baik itu pendidikan formal maupun nonformal, di dalam proses pembelajarannya tidak lepas antara teori dan praktik dimana kedua hal tersebut saling menunjang dalam pencapaian hasil pembelajaran yang optimal. Karena pada setiap manusia yang belajar itu mengharapkan agar dirinya memperoleh pengetahuan, keterampilan dan mampu memecahkan persoalan-persoalan yang dihadapinya, namun perlu 
diingat bahwa hasil belajar yang diperoleh seseorang itu sangat berkaitan dengan cara, kebiasaan serta proses belajar itu sendiri dan peran seorang guru yang senantiasa memberikan arahan dan bimbingan kepada anak didiknya demi tercapainya tujuan yang diinginkan.

Seperti yang diungkapkan oleh Moh. Uzer Usman (2008:4) menyatakan bahwa Salah satu cara untuk mencapai tujuan pendidikan adalah melalui proses belajar mengajar. Proses belajar mengajar merupakan suatu proses yang mengandung serangkaian perbuatan guru dan siswa atas dasar hubungan timbal balik yang berlangsung dalam situasi edukatif untuk mencapai tujuan tertentu. Untuk itu peningkatan kualitas sumber daya manusia sangat membutuhkan adanya kontribusi yang besar sebagai out put dari proses pendidikan yang dilakukan. Perkembangan ilmu pengetahuan dan teknologi dewasa ini mempunyai dampak yang nyata pada kebutuhan akan pentingnya pendidikan bagi seluruh bangsa Indonesia. Sasaran yang hendak dicapai pemerintah Indonesia yang merupakan tujuan nasional sebagai mana tertera dalam Undang-undang RI nomor 20 tahun 2003 tentang sistem pendidikan nasional (2013:8) pada pasal 3 yang berbunyi : Pendidikan nasional berfungsi mengembangkan kemampuan dan membentuk watak serta peradaban bangsa yang bermartabat dalam rangka mencerdaskan kehidupan bangsa, bertujuan untuk berkembangnya potensi peserta didik agar menjadi manusia yang beriman dan bertaqwa kepada Tuhan Yang Maha Esa, berakhlak mulia, sehat, berilmu, cakap, kreatif, mandiri dan menjadi warga Negara yang demokratis serta bertanggung jawab.

Biologi sebagai salah satu pembelajaran di sekolah merupakan bagian dari ilmu pengetahuan alam yang mengkaji tentang makhluk hidup beserta 
lingkungannya. Dalam pembelajaran biologi, siswa diperkenalkan dengan makhluk hidup beserta lingkungannya. Untuk itu, Guru harus mampu mengelola suatu kegiatan belajar mengajar dengan menggunakan pendekatan pembelajaran yang dapat melibatkan siswa agar aktif baik secara fisik maupun mental dalam rangka memperoleh pengalaman belajar. Dalam suatu kegiatan mengajar tidak terlepas dari aktivitas guru dalam menyampaikan informasi dan siswa menerima informasi tetapi siswa juga mengelola informasi yang mereka terima dengan terlibat langsung dan aktif dalam kegiatan belajar mengajar sebagai usaha meningkatkan kemampuan belajar.

Berdasarkan observasi dan wawancara yang penulis laksanakan di SMA Negeri 3 Kerinci diperoleh keterangan nilai rata-rata ulangan semester ganjil matematika siswa kelas $\mathrm{X}$ masih tergolong rendah, hal ini disebabkan karena siswa tidak begitu berminat dengan pelajaran biologi, mereka cepat merasa jenuh karena pendekatan pembelajaran yang diterapkan masih belum memberikan motivasi bagi siswa untuk lebih semangat lagi dalam belajar. Keterampilan metakognitif juga perlu dikuasai oleh guru agar siswanya dapat memiliki keterampilan metakognitif yang tinggi. Karena keterampilan metakognitif memungkinkan siswa untuk melakukan perencanaan, mengikuti perkembangan, dan memantau proses belajaranya.

Metakognisi juga melatih siswa untuk bersikap jujur, berani mengakui kesalahan, dan menilai kemampuan diri sendiri. Pembelajaran yang dapat memberdayakan potensi peserta didik seperti pemberdayaan berpikir metakognitif namun di SMA Negeri 3 Kerinci belum dilaksanakan secara maksimal sehingga proses pembelajaran menjadi kurang bermakna. Peserta 
didik lebih cenderung pasif di kelas dalam menerima pelajaran, lebih banyak diam, mendengar, mencatat, menghafal, bahkan peserta didik cepat merasa bosan dan akhirnya tidak bersungguh-sungguh mengikuti proses pembelajaran. Kondisi seperti ini dapat berdampak kepada kemandirian peserta didik dalam belajar, sehingga siswa kurang terlatih dan tidak berkembang.

Untuk itu perlu adanya solusi dalam meningkatkan hasil belajar siswa salah satunya dengan memberikan motivasi dengan menerapkan pendekatan pembelajaran yang lebih menarik dalam pelajaran biologi. Terdapat berbagai macam pendekatan pembelajaran yang dapat digunakan dalam pembelajaran diantaranya adalah pendekatan pembelajaran Bridging Analogy yang dapat meningkatkan kemampuan metakognitif siswa dalam belajar.

Menurut Intan irawati, Analogi adalah model penjelasan suatu konsep atau topik dengan cara menganalogikan dengan suatu peristiwa yang mudah dimengerti oleh siswa. Model ini menggunakan pendekatan konstruktivisme. Guru dapat menjelaskan konsep sulit dan abstrak melalui pendekatan ini. Proses berpikir siswa diarahkan dengan analogi yang sesuai dengan pokok bahasan untuk membentuk konsep, bernalar, berpikir kritis, membuat keputusan, berpikir kreatif dan memecahkan berbagai soal dalam pembelajaran biologi. Kehadiran analogi mutlak diperlukan, khususnya jika materi ajar berhubungan dengan wilayah di luar jangkauan panca indera manusia atau alat bantu visual untuk pengamatan.

Menurut Apit Fatthurohman, Beberapa kelebihan mengajar menggunakan analogi yakni: 1. Sebagai alat untuk mengajarkan perubahan konseptual, 2. Analogi menyediakan visualisasi dan pemahaman pada konsep 
yang abstrak yang merujuk pada contoh-contoh dalam kehidupan nyata, 3 . Analogi mungkin memicu minat belajar siswa karenanya memiliki efek motivasi, 4. Analogi menuntut guru untuk mempertimbangkan prakonsepsi siswa terhadap materi yang akan diajarkan serta dapat mengeleminasi atau mengurangi ketidakpahaman pada materi yang diajarkan.

\section{B. METODELOGI PENELITIAN}

Jenis penelitian yang digunakan adalah eksperimen. Penelitian Eksperimen merupakan satu-satunya metode penelitian yang dapat menguji secara benar hipotesis menyangkut hubungan kausal (sebab akibat). Berdasarkan hal di atas maka rancangan penelitian yang penulis gunakan adalah dengan menggunakan dua kelas, yaitu kelas eksperimen merupakan kelas yang menggunakan pendekatan pembelajaran bridging analogy untuk meningkatkan kemampuan metakognitif dan kelas kontrol merupakan kelas tanpa diberikan perlakuan.

Populasi yang ditentukan dalam penelitian ini adalah seluruh siswa kelas X SMA Negeri 3 Kerinci yang berjumlah 47 orang siswa. Sampel adalah sebagian atau wakil populasi yang diteliti. Karena dibutuhkan dua kelas sampel maka penulis menentukan sampel dengan cara menggunakan teknik random sampling. Namun, sebelum pengambilan sampel, terlebih dahulu dilakukan uji normalitas (uji Lilifors) dan uji homogenitas populasi (uji Barlett).

Variabel dalam penelitian ini adalah sebagai berikut: 1. Variabel bebas adalah variabel yang mempengaruhi variabel lain. Variabel bebas dalam penelitian ini adalah pendekatan pembelajaran bridging analogy. 2. Variabel 
terikat variabel yang dipengaruhi oleh variabel bebas. Variabel terikat dalam penelitian ini adalah nilai peserta didik setelah diberikan tes.

Instrumen penelitian adalah segala sesuatu yang dapat digunakan sebagai alat pengumpul data atau informasi karena memang banyak cara yang dapat dilakukan untuk mengumpulkan suatu informasi yaitu:

\section{a. Tes Hasil Belajar}

Tes hasil belajar yang peneliti gunakan dalam penelitian ini yaitu tes yang berbentuk soal pilihan ganda atau objektif, yang diuji coba terlebih dahulu di sekolah yang berbeda untuk mengetahui tingkat kesukaran, daya beda, validitas dan reliabilitas soalnya, sebelum dipakai di sekolah tempat meneliti.

b. Teknik Inventori

Pada teknik inventori, posisi subjek direpresentasikan dengan item pertanyaan atau peryataan yang menggambarkan bentuk tingkah laku seseorang. Pada tes inventori ini subjek diminta untuk menunjukan apakah masing-masing pertanyaan atau pertanyaan merefleksikan tingkah laku mereka, dengan menjawab ya atau tidak; sangat setuju, setuju, tidak setuju, dan sangat tidak setuju. Jawaban yang mereka berikan kemudian kemudian dihitung melalui angka jawaban yang sesuai dengan sifat-sifat yang peneliti hendaki ukuran.

Teknik inventori juga digunakan untuk mencari hubungan antara variabel, yang berkaitan dengan kegiatan dalam pendidikan termasuk, misalnya inteligensi, pencapaian hasil belajar, sikap, persepsi, motivasi, dan sebagainya. Selain itu, tes inventori juga banyak digunakan untuk menggambarkan status atau kondisi responden yang ada pada waktu tertentu. Untuk mengukur perubahan kondisi sebagai akibat perubahanya faktor-faktor penyebab dan juga untuk memprediksi 
tingkah laku yang akan datang atas dasar perfarmasi saat ini, (Sukardi, 2010:143). Setelah data terkumpul, tahap selanjutnya adalah menganalisis data dan interprestasi hasil. Tahap analisis meliputi: 1.Uji Normalitas, 2. Uji Homogenitas dan 3. Uji Hipotesis.

\section{HASIL PENELITIAN DAN PEMBAHASAN}

Adapun kemampuan metakognitif siswa pada kelas eksperimen yang menggunakan pendekatan pembelajaran bridging analogy diperoleh dari tes akhir pada tabel berikut:

Tabel 1. Kemampuan Metakognitif Siswa Pada Mata Pelajaran Biologi Berdasarkan Distribusi Hasil Angket Kelas Eksperimen Yang Menggunakan Pendekatan Pembelajaran Bridging Analogy

\begin{tabular}{|l|l|l|}
\hline No & Rerata & Nilai \\
\hline 1 & jumlah nilai $\sum \mathrm{x}$ & 2830 \\
\hline 2 & nilai rata-rata $\bar{x}$ & 123,04 \\
\hline 3 & nilai varians $\left(\mathrm{S}^{2}\right)$ & 158,89 \\
\hline 4 & nilai simpangan baku $(\mathrm{S})$ & 12,61 \\
\hline
\end{tabular}

Dari Tabel 1 diperoleh jumlah nilai $=2830$, nilai rata-rata $=123,04$, nilai

varians $\left(S^{2}\right)=158,89$ dan nilai simpangan baku $(S)=12,61,$. Jika dilihat dari nilai rata-rata yang diperoleh siswa menunjukkan kemampuan keterampilan metakognitif siswa menggunakan pendekatan pembelajaran bridging analogy sudah tinggi dan hampir semua siswa sudah tuntas pada mata pelajaran biologi di SMA Negeri 3 Kerinci tahun pelajaran 2015/2016.

Selanjutnya, pembelajaran konvensional pada umumnya memiliki kekhasan tertentu, misalnya lebih mengutamakan hafalan daripada pengertian, menekankan pada keterampilan berhitung, mengutamakan hasil daripada proses, dan pengajaran berpusat pada guru. Kelemahan pembelajaran konvensional yaitu 
siswa menjadi pasif, pembelajaran didominasi oleh guru dan tidak banyak mendapat umpan balik atau cenderung searah, dan siswa kurang mengerti materi yang disampaikan guru.

Tabel 2. Kemampuan Metakognitif Siswa Pada Mata Pelajaran Biologi Berdasarkan Distribusi Hasil Angket Kelas kontrol Tanpa Menggunakan Pendekatan Pembelajaran Bridging Analogy

\begin{tabular}{|c|c|c|}
\hline No & Rerata & Nilai \\
\hline 1 & $\sum \mathrm{x}$ & 2680 \\
\hline 2 & $\bar{x}$ & 111,66 \\
\hline 3 & $s^{2}$ & 173,91 \\
\hline 4 & 5 & 13,19 \\
\hline
\end{tabular}

Dari Tabel 2 diperoleh jumlah nilai $=2680$, nilai rata-rata $=111,66$, nilai varians $\left(S^{2}\right)=173,91$ dan nilai simpangan baku $(S)=13,19$. Jika dilihat dari nilai rata-rata yang diperoleh siswa menunjukkan kemampuan keterampilan metakognitif siswa tanpa menggunakan pendekatan pembelajaran bridging analogy lebih rendah dibandingkan menggunakan pendekatan pembelajaran bridging analogy pada mata pelajaran biologi di SMA Negeri 3 Kerinci tahun pelajaran 2015/2016.

\section{BOX PLOT}

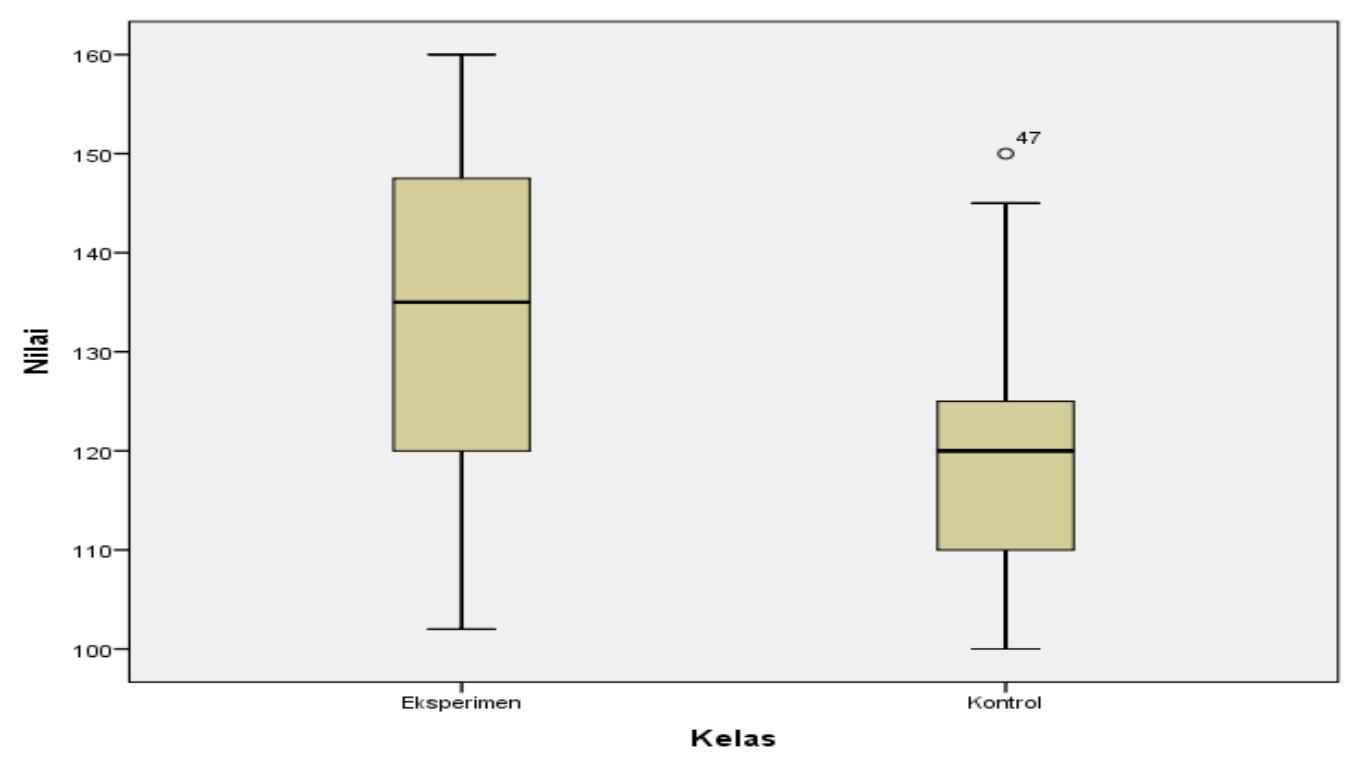


Hal ini dikarenakan peserta didik lebih tertarik mengikuti pembelajaran menggunakan pendekatan pembelajaran bridging analogi di kelas dibandingkan dengan strategi pembelajaran konvensional. Dimana, pendekatan pembelajaran bridging analogi lebih menekankan agar siswa lebih aktif dalam proses pembelajaran di kelas sedangkan pada pembelajaran konvensional siswa lebih banyak pasif. Hal ini menunjukkan bahwa Terdapat pengaruh dalam penerapan pendekatan pembelajaran bridging analogy untuk meningkatkan kemampuan metakognitif siswa SMA Negeri 3 Kerinci tahun pelajaran 2015/2016.

Setelah dilakukan analisis data, diperoleh nilai $t_{\text {hitung }}=2,65$ dan nilai $t_{\text {tabel }}$ $=1,68$ ternyata $t_{\text {hitung }}>t_{\text {tabel }}$. Hal ini berarti $\mathrm{H}_{0}$ ditolak dan $\mathrm{H}_{1}$ diterima sehingga dapat disimpulkan bahwa Terdapat pengaruh dalam penerapan pendekatan pembelajaran bridging analogy untuk meningkatkan kemampuan metakognitif siswa SMA Negeri 3 Kerinci tahun pelajaran 2015/2016 pada tingkat kepercayaan $95 \%$.

\section{Kesimpulan}

Dari hasil penelitian yang telah dilakukan, maka penulis merumuskan kesimpulan penelitian sebagai berikut:

1. Kemampuan metakognitif biologi siswa SMA Negeri 3 Kerinci dengan menggunakan pendekatan pembelajaran Bridging Analogy sangat baik.

2. Kemampuan metakognitif biologi siswa SMA Negeri 3 Kerinci tanpa menggunakan pendekatan pembelajaran Bridging Analogy kurang baik. 
3. Setelah dilakukan analisis data, diperoleh $t_{\text {hitung }}=2,65$ dan $t_{\text {tabel }}=1,68$ ternyata $t_{\text {hitung }}>t_{\text {tabel }}$. Hal ini berarti $\mathrm{H}_{0}$ ditolak dan $\mathrm{H}_{1}$ diterima sehingga dapat disimpulkan bahwa terdapat pengaruh dalam penerapan pendekatan pembelajaran bridging analogy untuk meningkatkan kemampuan metakognitif biologi siswa SMA Negeri 3 Kerinci pada tingkat kepercayaan $95 \%$.

\section{E. DAFTAR PUSTAKA}

ApitFatthurohman,http/jurnalinovasidanpembelajaranfisika/vol1/no.1/mei2014l SSN:2355-7109, (online), Diakses 4 Januari 2016.

Depertemen Pendidikan Nasional Republik Indonesia. 2003. Undang-Undang Republik Indonesia Nomor 20 Tahun 2003 Tentang Sistem Pendidikan Nasional. Jakarta: Depertemen Pendidikan Nasional Republik Indonesia.

Intan irawati, http/scholarworks.umass,edu/journal/AA1880965, (Online). Diakses 4 Januari 2016.

Sukardi, 2010. M etodelogi Penelitian Pendidikan, Jakarta : Bumi Aksara.

Moh. Uzer Usman. 2008. Menjadi Guru Profesional. Bandung: PT. Remaja Rosdakarya.

Sukardi, 2010. Metodelogi Penelitian Pendidikan, Jakarta : Bumi Aksara. 